Please cite this article as: Chandler, Rebecca C. and Robinson, Oliver C., Wellbeing in retirement villages: Eudaimonic challenges and opportunities, Journal of Aging Studies (2014), doi: http://dx.doi.org/10.1016/j.jaging.2014.08.001

NOTE: This is a PDF file of an unedited manuscript that has been accepted for publication. The manuscript will undergo copyediting, typesetting, and review of the resulting proof before it is published in its final form. Please note that during the production process errors may be discovered which could affect the content, and all legal disclaimers that apply to the journal pertain.

\title{
Wellbeing in retirement villages: Eudaimonic challenges and opportunities
}

Chandler, Rebecca C.

School of Health \& Social Care,

University of Greenwich,

Avery Hill Road, London, SE9 2UG, UK

United Kingdom

R.C.Chandler@greenwich.ac.uk

Tel: +44 (0)7584496837

Robinson, Oliver C.

Department of Psychology and Counselling,

University of Greenwich,

Avery Hill Road, London, SE9 2UG, UK

United Kingdom

o.c.robinson@gre.ac.uk

Tel: +44 (0)2083319630

Fax: +44 (0)2083319160

\begin{abstract}
A retirement village consists of a collection of privately owned or leased flats or maisonettes for elderly adults that are supported by a central hub that provides catering, medical care and social activities. There have been studies of the psychological experience and impacts of such environments, however, there is lack of research that links the retirement village experience to overarching theories of eudaimonic wellbeing, and that uses qualitative methods to find out
\end{abstract}


Running title: Wellbeing in retirement villages

about how wellbeing manifests for the individual. This study used Ryff's (1989) model of wellbeing as a framework for analysis, while aiming to gain an in-depth understanding of the experiences and sources of wellbeing in residents of two retirement villages in the South East of England. Semi-structured interviews were carried out with 18 residents. Thematic analysis revealed a dialectical tension to retirement village living: while facilitating all six core components of eudaimonic wellbeing as conceptualized by Ryff's model, individuals living within the retirement villages also experience challenges to wellbeing on the same dimensions. An integrative model of these tensions between positive and negative experiences is presented and discussed.

Key words: Retirement village, wellbeing, aging, eudaimonic 


\section{Wellbeing in retirement villages: Eudaimonic challenges and opportunities}

The landscape of supported accommodation for the elderly in the UK has changed radically over the past two decades. One of the forms of residence that has increased in prevalence over this time is the 'retirement village' model (Grant, 2007). In a retirement village, elderly residents either own or rent a self-contained apartment or maisonette within a larger community that contains facilities such as dining, leisure and care services. A monthly or annual fee is paid to the community provider for access to these services (Robinson, 2012). In 2009, the BBC published a report that suggested that 25,000 older adults lived in a retirement village on that date ${ }^{1}$, and that number is likely to have increased markedly since then, as villages continue to be built all over the country. The lower age limit for entry into a retirement village is typically set at 55 or 60 , but the average age is around 80 (Evans, 2009). Retirement villages are a relatively new social milieu that are likely to be different in their effects on wellbeing and identity, compared with more traditional forms of elderly care environment, due to the greater emphasis on autonomy and on an absence of reference to being a 'care' home. The current study aims to explore how living in a retirement village within the UK is personally experienced by residents as impacting positively and negatively on eudaimonic wellbeing, using Ryff's taxonomic model of wellbeing as an orientating framework.

\section{Eudaimonic wellbeing}

Wellbeing is a complex construct that has been operationalized in different ways by psychologists and sociologists. Broadly, these different definitions can be categorized as either hedonic or eudaimonic. The hedonic approach, associated with Epicurus and the utilitarian philosophy of Bentham, defines wellbeing as the subjective experience of pleasure

\footnotetext{
${ }^{1}$ BBC One program - 'Silverville' - accessed August 5, 2009
} 
and satisfaction, and in psychology this has been operationalized in the construct of 'subjective wellbeing' (SWB) (Bauer \& Park, 2010). SWB contains the emotional dimensions of happiness, the balance between positive/negative affect, and the cognitive dimension of life-satisfaction (Daatland, 2005). In contrast, eudaimonic wellbeing originates in Aristotelian philosophy and is concerned with optimal experience and functioning in a broader sense than the hedonic type, including positive relationships, a sense of purpose, meaning, and a feeling of growth, as well as the hedonic cognitive-affective appraisals of happiness and satisfaction. In psychology, the eudaimonic conceptualization has been operationalized in psychological wellbeing (PWB), by Ryff (1989).

Ryff conceptualized a model of eudaimonic wellbeing based on the following six dimensions: purpose in life, personal growth, self-acceptance, environmental mastery, autonomy and positive relations (Ryff, 1989; Ryff \& Singer, 2008). Self-acceptance refers to having a positive attitude towards oneself and one's life, past and present and accepting one's positive and negative attributes (Ryff\& Singer, 2008). Positive relations refers to having trusting and satisfying relationships, and the ability to empathize with others (Ryff \& Singer, 2008). Personal growth subsumes feelings of continued self-development and a sense of actualising one's highest potentials. Purpose of life is concerned with having goals, sense of vocational direction, and the feeling that life has meaning (Ryff \& Singer, 2008).

Environmental mastery relates to feelings of competence in environmental management, controlling and engaging in external activities, and choosing environments suitable to personal needs and values. Finally, autonomy refers to being self-determining and independent, resisting social pressures, and evaluating one's self by personal standards (Ryff \& Singer, 2008).

Research has supported the presence and importance of Ryff's (1989) core dimensions in older adults. In a mixed-method study, Johannesen, Petersen and Avlund, 
(2004) found the six wellbeing dimensions in a group of physically frail 85-year olds; they expressed wellbeing when they are meaningfully occupied, have friends, feel able to manage their own life, do not live alone, and have not lost friends recently (Johannesen et al., 2004). Hahn and Oishi (2006) found that older adults who were asked to recall the "most satisfying" event they had experienced in the past month identified an event which related to autonomy, competence in their environment, and relatedness with others. Support for the importance of autonomy has been evidenced by lower levels of depression and higher adaption in older adults who perceive they have high levels of control and self-determination in their lives (Johnson \& Barer, 1997; Altintus \& Guerrien, 2009).

The six components have also been compared across the lifespan to determine the relationship of wellbeing to aging (Ryff\& Keyes, 1995). It has been found that autonomy and environmental mastery increase with age. However, self-acceptance and positive relations remain stable, while purpose in life and personal growth show sharp declines after midlife (Ryff \& Keyes, 1995). Ryff and Singer (2008) attributed these declines to societal challenges in providing older adults with meaningful roles and opportunities for continued growth. This view seems to be supported, as those older individuals who occupy roles in later life have a higher sense of purpose than older individuals who do not occupy productive roles (Greenfield \& Marks, 2004). Furthermore, qualitative evidence indicates that dementia sufferers are able to maintain meaningful lives and demonstrate ongoing personal growth (Henderson \& Andrews, 1998; Harris, 2008).

A longitudinal study conducted by Kling, Seltzer \&Ryff (1997) explored the impact of relocation on older women's eudaimonic wellbeing, using Ryff's six dimensions as a framework. Two challenges for this age group were explored; relocation to a new residence, and caregiving for a learning disabled child. It was found that the relocation sample showed increases in environmental mastery and personal growth over time, while the same was not 
found in the caregiving sample. Overall the study showed the applicability of Ryff's wellbeing dimensions to longitudinal change, and emphasized the relevance of a multidimensional eudaimonic approach to wellbeing in the elderly.In summary, Ryff's taxonomic model of wellbeing has provided a flexible and applicable scheme for assessing wellbeing in relation to aging, and in the current study it is used to structure a qualitative analysis. It is important to emphasise that Ryff's model is a descriptive heuristic and not an explanatory theory - it divides the concept of eudaimonic wellbeing into six lower-level constructs that pertain to the 'good life' in a way that does not involve reporting happiness or satisfaction, and this helps to frame questionnaires or interviews about the topic and interpret findings in a way that is comparable with studies with different age groups and related topics.

\section{Retirement communities, supported accommodation, and wellbeing}

Retirement villages claim to provide an environment that promotes wellbeing and quality of life for their residents (Bernard, Liddle, Bartlam, Scharf, \& Sim, 2012). In support of this, research which has been conducted within retirement villages, and similar housing arrangements such as elder co-housing and assisted living, has found benefits to wellbeing including: increased social life and activities; reduction in feelings of loneliness; more manageable and suitable dwellings; peer support, reassurance from care and security; a sense of autonomy; positivity about living in an age-segregated community; opportunities for selfdiscovery, self-expression, self-development and rejuvenation; and overall higher quality of life than community dwellers (Biggs, Bernard, Kingston \& Nettleton, 2000; Buys, 2001; Gardner et al., 2005; Grant, 2007; Glass \& Vander Plaats, 2013; Sandhu, Kemp, Ball, Burgess \& Perkins, 2013).

Research has, however, also suggested retirement villages have negative consequences to wellbeing, including: limits to self-expression; complications in negotiating the social milieu; absence of youth; superficial settings; promotion of fear of the world and 
Running title: Wellbeing in retirement villages

'fortress mentality'; portraying an unrealistic process of aging; and producing social fragmentation (Kastenbaum, 1993; Gurney \& Mean, 1993; Laws, 1995; Katz, 1995; Hansen, 2001; McHugh, 2000; Gilleard \& Higgs, 2005; McHugh \& Larson-Keagy, 2005; Grant, 2007). Some authors have even dubbed retirement villages as 'grey ghettos' (Shapiro, 1999; Huber \& Skidmore, 2003).In addition, it has been suggested that relocation to supported living it later life might have negative psychological effects on older adults, as it may result in feelings of ambivalence, grief, loss and fear of impending losses and death (Golant, 2011; Ayalon \& Green, 2012).

Clearly there appears to be an ambiguity at the heart of the retirement village experience that requires further investigation. Quantitative methods are not well placed to explore contradictory and dialectical challenges of elderly care due to their reliance on linear relationships and either-or logic (Cutchin, 2005), thus this study takes a qualitative approach to the problem.

\section{Research Aims and Questions}

Existing research on wellbeing and positive experiences in retirement villages has a tendency to focus on specific aspects of village life using a quantitative methodology (Croucher, Hicks \& Jackson, 2006; Gardner et al., 2005). Based on what was perceived as a gap in the existing literature, this study aimed to gain a greater understanding of the experiences and self-reported sources of, and obstacles to, wellbeing of elderly adults living within retirement villages. This aim was explored using qualitative methodology, for which Ryff's (1989) model of wellbeing provided a thematic framework.

To fulfil the study's principal aim, the following research questions were formulated. The initial question was 'What experienced impact does moving to a retirement village have on wellbeing?' This aimed to explore the positive and negative consequences, and assess the credibility of the claim that villages promote wellbeing and quality of life. The second 
research question was 'What are the perceived sources of wellbeing within the village?', which aimed to explore the features and aspects of retirement villages that promote or undermine wellbeing.

\section{Method}

\section{Participants}

Participants were recruited from two retirement villages in the South East of England. The villages were selected for being genuine 'villages', insofar they both are comprised of a collection of houses and apartments in different blocks, with a central amenity building (as opposed to a single block or home divided into apartments, which is used in some retirement communities). Plans of the two villages are shown in Appendix A. One village was only two years old at the time of data collection, and the other had been in use for 13 years. This was to include both a relatively established village, mainly comprising residents who have been there for many years, and a recently developed one with residents who were new to the retirement village environment. Residents were sent a postal letter that was approved by the organisation that owns the two villages, which asked if they would like to participate in an interview to discuss their experiences about life in a retirement village (the letter did not mention wellbeing, to avoid assumptions of focusing only on positive experiences). The letter invited them to participate in the study, or to contact the researcher first should they require further information. Those who wished to participate returned a reply slip, or contacted the researcher directly via the telephone. Exclusion criteria were applied in the recruitment of participants to exclude those who had recently experienced a traumatic life event, or those who were experiencing depression, due to the potential of the interview to cause or increase distress.

The study recruited 18 participants (14 female, 4 male), including 3 couples, 10 widows, a spinster and a single widower. This was felt to be an appropriate number for the 
Running title: Wellbeing in retirement villages

sample in question, given the balance of wanting to explore and convey individual experiences in the report while also establishing cross-case themes and regularities (Robinson, 2014). The predominance of females reflects the demographic make-up of the retirement village. Participants' ages ranged from 68-99 years of age (mean: 79 years old) and duration of residency varied from less than 1 year to up to 12 years (mean: 4 years). A summary presentation of the participants' pseudonyms, age, residency duration and reason for transitioning into the retirement village is provided in Table 1.

\section{[Insert Table 1]}

\section{Data Collection \& Procedure}

Following receipt of a participation reply slip, or confirmation via telephone, the researcher arranged interviews in the participants' homes. Data was collected using semistructured in-depth interviews which were carried out either individually (for 10 widows, 1 spinster, and 1 widower) or with couples ( 3 interviews). Prior to commencing the interview, participants received an information sheet, and if they still wished to participate following this, they were given a consent form to provide fully informed written consent. Interviewees who were partially sighted were read all forms by the researcher. Interviews were audio recorded for later transcription and lasted from 15 minutes to over 2 hours, depending on interviewees' communication abilities and health (average interview time was 1 hour 10 minutes). The interviewer asked participants a selection of questions about their experiences of living in the village following an interview topic guide constructed prior to commencement of the study. All participants were free to decline to answer any questions, cease the interview, and withdraw themselves at any point during the process. On completion of the interview participants were debriefed using a debriefing sheet and reminded of their right to withdraw their data within two weeks from the interview. Interview audio was 
Running title: Wellbeing in retirement villages

transcribed, pseudonyms were used and all identifying features were removed from transcripts to protect participants' anonymity.

\section{Analysis}

Analysis of transcribed interview audio was carried out according to the tenets of thematic analysis (Braun and Clark, 2006). The process followed the six steps in the analysis of each interview transcript outlined by Braun and Clark (2006): generation of initial codes; search for themes; reviewing themes; defining and naming themes; and finally producing the final analysis. One researcher acted as primary analyst, and the second researcher acted as a secondary analyst, discussing a selected number of interviews in detail and giving input to the allocation of data to thematic categories.

Thematic analysis can be conducted using a deductive or inductive focus on theme development (Braun and Clark, 2006). An inductive focus means that themes are developed following early analysis of the data, in ways that are idiosyncratic to the topic under study; this confers the advantage of an open-ended and exploratory focus to analysis, and avoids any inappropriate categorisation of data into a-priori themes that do not reflect the content of the interviews. In contrast, a deductive analysis means that themes come from an existing theory or set of constructs prior to analysis commencing. The advantage of a deductive approach is that the results are easily incorporated into an existing corpus of literature, and compared/contrasted with other studies that have used the theory. Both inductive and deductive thematic analyses have different merits, but a deductive focus was chosen for the current study, to ensure strong links with existing literature on wellbeing and aging. However, the analysts were open to the development of additional or revised categories if required. In the event, this was not necessary. 


\section{Results}

The thematic analysis of participants' interview narratives conveyed how the retirement village environment is subjectively experienced as influencing wellbeing in both positive and negative ways, and these could be well accounted for by the opposing ends of the Ryff's (1989) six dimensional wellbeing model. These components were thus used as labels for the higher-order cross-case thematic categories in the analysis, without need for change or addition. The participants' accounts referred to ways that life in a retirement village could enhance wellbeing on these six dimensions, but also decrease it, suggesting that such environments contain both opportunities for enhancing or decreasing the quality of life of their residents. These tensions are presented within Figure 1 - the positives and negatives within each box of the diagram illustrate the 'dialectical' key relational form in qualitative analysis (Robinson, 2011). A detailed description of how these six wellbeing dimensions manifested in positive and negative ways within the data is given below with illustrative quotes.

[Insert Figure 1 here]

\section{Self-acceptance}

Self-acceptance involves taking a positive and unconditional regard to oneself, one's past, and one's possible future (Ryff \& Singer, 2008).Living in a retirement village was described as conducive to a sense of acceptance, as it provided for the redefinition of what it means to be old. Young and old are relative terms, and in an environment where the average age is very high, old people can redefine themselves as young, and can create their own redefined norms of aging. Betty described this as follows, referring to the retirement village as the 'walled garden' to emphasize its special and secluded nature:

"But here in the walled garden we're not old and doddery. We are just in this situation." (Betty. Aged 68. Married). 
Furthermore, acceptance of the self, and promotion of positive self-regard, is facilitated by a sense of togetherness and shared lives with fellow residents. Participants emphasised the shared similarities in experience, lifestyle, and age, thus describing an environment in which residents accept each other. For example Emma emphasises the solidarity of being with mostly women:

"At least you understand each other, I mean you know women, it's like in a way being back at school, you are all in the same boat, we are all widows, we have all given up bigger houses and come here, and people I think our age tend to make the best of things, you don't forever be harking back and saying oh it was better then, you do to yes when you were a child or a teenager, but I think people get on with it better as they get older, they accept that this is how it's going to be." (Emma. Aged 76. Widow).

Conversely, the retirement village can threaten interviewees' positive self-acceptance due to the ever-present reminders of morbidity and mortality, and its resemblance to a care home. James and Lily describe this as follows:

"When you see the ambulance continually pulling up and people going to hospital and then you go to the cremation or the funeral and so on that has a depressing effect on your mind." (James. Aged 89. Married)

"I didn't know anybody, faced with lots of old ladies, and slightly depressing to look at it.... some are away with the fairies, and it was depressing to be reminded of one's own mortality seeing everybody hovering about on walking frames." (Lily. Aged 83. Widow)

The emotional impact of these mortality reminders shows that a serene acceptance of one's life in a retirement village is frequently offset by experiences that are hard to accept and come to terms with.

\section{Positive Relations}

Interviewees described experiencing positive relations within their respective retirement villages, while also experiencing social divisions. The villages provide opportunities to form new friendships, facilitated by communal areas and activities, and the presence of residents of 
similar backgrounds and age. Betty particularly focuses on friendship-formation, and how that is facilitated by the village:

"Yes, and really our friends, and we've made new friends here, is what has made us, and continues to make us happy. We weren't friendless and then made friends here, we've just enlarged our friendship circle." (Betty. Aged 68. Married).

Ellen similarly describes how the people in the village are central to her sense of wellbeing there.

"I think it's the people, I think they are extremely nice people to start with and we are all in the same boat and we all get together and we have a lot of fun. But everyone's very tactful and you never hear anyone saying anything about anyone else, which is very nice, very tactful, very nice people all around, and if they don't want to mix then they don't and everyone respects that." (Ellen. Aged 89. Widow).

Ellen portrays an experience of strong communal relationships within her village, emphasising experiences of togetherness, empathy, mutuality of relationships, and respect.

These same terms having been used by Ryff (1989) to define the positive relations dimension, suggesting the retirement villages promote this component of wellbeing.

On the other end of the spectrum, participants also expressed challenges in the social milieu of their respective villages. Clear divisions between groups of residents are present, and as a result of these groups and cliques, exclusion and friction can occur. This can lead to some residents, particularly new ones, being ostracised. Three examples of this experience are described below:

"The people in the houses which are in the walled garden, they are a very contained bunch and of course they get to know one another very much sooner than we in the flats do... But already you see that has made a division. It's so funny I laugh about it and we pull each other's legs, but it is a division." (Anne. Aged 85. Married)

"I still feel that there is this thing there, 'you sit next to me'...Don't get me wrong it doesn't worry me, but I just ... there is somewhere along the line I just feel that I might not belong to their clique." (Dorothy. Aged 84. Widow) 
"You get...people forming little cliques and you get people, perhaps six or eight people who seem to think they do everything together and somebody leads them....and then of course they don't speak to her and you sort of think well blow that I speak to everybody you know! I can't be doing with that, but it happens and people do complain about it, especially if they are not part of the clique. Anybody new coming in I think it can be difficult." (Martha. Aged 85. Widow)

Furthermore, participants describe how forming positive relations can be difficult in the village, as some residents find it difficult to socialize due to age-related issues. This leads to an appraisal of there being 'two camps' in the village, which can lead to a sense of 'them and us';

"Well I find there are two varieties (of people) you know. There is one as I say who are friendly and outgoing, there are some who shut themselves away either because they are infirm or they don't want company which is what this place is for really." (Lily. Aged 83. Widow).

In summary, retirement villages provide a high level of opportunity for friendship formation, however the communal environment leads to social divisions that can be experienced negatively.

\section{Personal Growth}

Personal growth is a continual process of developing oneself, and being willing to meet new challenges across the lifespan (Ryff \& Singer, 2008). The majority of interviewees referred to experiences that fit within this wellbeing component. They describe how they see the retirement village as facilitative of personal growth, by providing opportunities to learn and be effective. One interviewee, Dorothy, states:

"I tell you what, on the odd times when I have something or another, and I am a bit perhaps not sure whether I can do it or something, I sit there and I look up like that and I see my husband and he says you can do it girl, you can do it girl! And that's it, I get on and do it! If I know I can do it, that's it, it is surprising what you can make yourself do." (Dorothy. Aged 84. Widow). 
Dorothy indicates her determination to continue growing and doing new things. However, personal growth can be hindered by the retirement village. Emma indicates that she has given up painting since being in the village due to the lack of space.

"No, no, no I have given up the ... I haven't got any oil paints here, no there is no room here is there, there is no room to store stuff. Now that is if you are looking for what is bad about coming here is the storage. I used to have a garage, an attic, and there is really no ... I haven't even got a suitcase here, there is no room to put one, so storage is ... you are very limited with what you can actually have." (Emma. Aged 76. Widow).

Ellen conveys how being in the village, despite providing activities, can reduce ambition to engage and the availability of resources that would be present in a large house or home.

\section{Purpose in Life}

Purpose in life is manifest in setting meaningful goals for oneself, either in the short-term or long-term (Ryff \& Singer, 2008). For many interviewees their appreciation of life, and continuing to appreciate and find interest in every day provides an ongoing sense of purpose:

"I'd love to live to be 100 , a lot of people say oh I am ready to die, I don't want to die.... I think life is just so special that as long as I can be here in the world and see what's going on and be interested in things that are going on." (Kate. Aged 89. Married)

For other interviewees they have concrete activities which give them a sense of purpose, as Betty describes.

"I always have something going on.... No, I've got a purpose of living, and I can't see that going away. Not yet, there is still too many things I want to see completed." (Betty. Aged 68. Married)

The retirement village context fosters this kind of purpose by providing activities and comforts that are appreciated. However, for a few interviewees, finding or maintaining their sense of purpose in life can initially be challenged by their move to the retirement village. 
Anne highlights how in moving to the village she found herself without a meaningful goal, which was a challenge to her sense of wellbeing:

"It was so peculiar when we moved in here, because all the things I'd had to get up to do - all the things weren't there anymore, so you have put your finger right on it. Getting out of bed in the morning and not having lots to do."(Anne. Aged 85. Married).

\section{Environmental Mastery}

Environmental mastery stems from an experience of feeling competent and in control within one's surroundings (Ryff \& Singer, 2008).The feeling of safety that comes with living in a retirement village helps residents to feel capable and in control, as described by Dorothy below:

"Not having too many problems, feeling safe, this is it I think it's feeling safe, being able to cope and all the rest of it. I am still with it, I am still capable of doing everything for myself. To be quite honest when I do something, if I do something, I get a feeling of wellbeing, I coped with that myself." (Dorothy. Aged 84. Widow).

On the other hand, for some participants the structured nature of the retirement village and its appeal to less able adults can evoke a perception of dependency. Ellen describes how there is a fine line between the retirement village and a nursing home:

"You see it becomes more ... when they advertise them as retirement homes they will give you the lovely picture of someone of 65 and 70 and being rather young for their age doing all sorts of things, well that disappears when they get to about 80 and then it becomes more like a nursing home if you are not careful, except you have got your own home." (Ellen. Aged 89. Widow).

A minority of interviewees whose health and mobility were declining felt that the village was not enough to give them a sense of control. Eric describes his declining ability to control and manipulate his environment below.

"My problem now is I am almost incapacitated. I can't walk without a walker. I can't walk without grabbing onto a side rail. I can't move 
outside of this room, and I am getting very depressed as a result of being on my own. Ten years ago I used to be able to paint paintings."(Eric. Aged 82. Widower).

\section{Autonomy}

Autonomy is derived from a sense of self-determination and making informed choices (Ryff \& Singer, 2008). Retirement villages are designed to maximize autonomy through choices of eating, lifestyle and routine. That is one of their great attractions for those who move in, who might otherwise be considering a more structured care environment. Norah summarises the feeling that they are able to be self-determining and the importance of this to them. That which provides a sense of autonomy is scaled back to small achievements such as being able to go out to the pub on one's own, which in turn means that the internal appraisal of being autonomous is protected despite age-related immobility or changes in activity level.

"I come in and I feel I have been out, I have done it, you know I have been to the pub, even if my friend Jane is not there.... I have been out for a couple of hours, and I get quite a kick that I am still capable of doing that." (Dorothy. Aged 84. Widow).

While autonomy appears to be fostered effectively for most within the retirement village,

there is a concern that outsiders perceive them as not independent, as Karen describes:

"People don't perceive me as being as independent as before I think. I do.... people, acquaintances, you know when you meet somebody and they ask you where do you live and you say oh a retirement village they might think ... they are wondering why is she there and then ... you know ... then they do perceive you a little bit differently I think than if I was in a flat somewhere." (Karen. Aged 77. Widow).

It is not only outsider perceptions which threaten interviewees' sense of autonomy. The presence of less able residents (as discussed in self-acceptance) encourages a sense of foreboding with regards to losing autonomy to the aging process. Anne describes this apprehension, with an attitude of helplessness, an anxiety shared by many interviewees.

"You talk about sadness and worry but you dread it if you become completely disabled and you are in the hands of whoever is your carer. 
That's an awful thing I think, but there you are." (Anne. Aged 85. Married).

Thus, while interviewees can articulate their experiences of autonomy within their retirement villages, they are aware that this may change at any time.

\section{Discussion}

This study aimed to explore how retirement villages influence wellbeing in terms of what residents consider to be the main sources of, and obstacles to, positive wellbeing. It was found that the retirement village environments studied here contain both perceived sources of wellbeing, and hindrances to wellbeing, and that the complex tapestry of experiences described by residents relate specifically to the socio-physical context of the village. Ryff's model provides a satisfactory taxonomy for understanding these wellbeing-related experiences, supporting other research conducted with both quantitative and qualitative data that suggest it to be a valid and useful model for exploring wellbeing in older adults (Ryff \& Keyes, 1995; Kling, Seltzer \& Ryff, 1997). Experiences that are conducive to wellbeing in the retirement village included: making new friends; feeling safe and protected; feeling young relative to other residents and the village environment; a sense of autonomy over one's affairs despite being in a protected space; and personal growth and mastery due to activities tailor made for elderly adults. It is notable that residents look to small everyday experiences of novelty or learning for growth or mastery experiences, suggesting the scaling back of goals described in disengagement theory (Cumming \& Henry, 1961) and gerotranscendence theory (Tornstam, 1989). Research has found that a sense of purpose typically declines in old age (Ryff \& Keyes, 1995), and it may be that village life can help re-foster a sense of purpose by providing age-appropriate activities and opportunities that other environments cannot. Feelings of self-acceptance in the village are noted by participants as being similar to before their time in the village, suggesting a constancy of this wellbeing dimension with age, in 
Running title: Wellbeing in retirement villages

support of other studies that have shown self-acceptance to be resilient in the face of aging (Ryff \& Keyes, 1995).

Negative impacts on wellbeing are described in the constant reminders of mortality within the village due to death, disability and illness in residents, a sense of being away from society, and the village being cliquey or socially divided. Both self-acceptance and environmental mastery can be negatively threatened by the move to the secluded 'walled garden' environment of the retirement village, away from productive social roles that may have been sources of esteem. Positive relations can also be limited by apprehension of other residents, difficulty with living in a communal environment that some residents equate with being like a school, and the beginning of withdrawal from activities, as disengagement theory would predict (Cumming \& Henry, 1961). Other threats to wellbeing include the absence of contact with younger generations. This gives some support to critics' claims that retirement villages are 'grey ghettos' devoid of youth and spontaneity (Laws, 1995; Katz, 1995; Shapiro, 1999; Huber \& Skidmore, 2003). Interviewees also expressed concerns that they sometimes feel as though they are within an institutionalised care environment, in line with critics who claim that the villages are an artificial environment and involve a 'fortress mentality' (Kaufman. 1993; Laws 1995; Katz, 1995).

The villages offer new sources of personal and social identity, and are tailored to suit the needs of those with declining health and mobility, thus reducing the impact of the aging process on wellbeing. This side of our findings gives weight to the claims that retirement villages provide an environment congruent with wellbeing in later life (Biggs et al., 2000; Croucher, et al., 2006; Bernard et al., 2012). However, elderly adults living within a retirement village do face some threats to their sense of wellbeing through difficulty adjusting, negotiating the divided social milieu of the village, and apprehensions of, and dissatisfaction with, an age-specific environment. These findings support some of the critics' 
observations about retirement villages, and past research which has highlighted the negatives of retirement community living (Gurney \& Mean, 1993; Hansen, 2001; Laws, 1995; Katz, 1995; Kastenbaum, 1993; McHugh \& Larson-Keagy, 2005).

The presence of all the dimensions of Ryff's (1989) model in the analysis indicates this environment provides sources of wellbeing in elderly adults congruent to a eudaimonic model. It shows that a socio-physical environment such as the retirement village can both facilitate and reduce wellbeing in its residents, and this dialectical tension relates to the complex interactions of person and environment, and the fact that differential appraisals of the same place lead to discrepant reported effects on wellbeing. However this dialectical 'doubleedged sword' is by no means inevitable in the future, and retirement villages would do well to explore how they can minimize the downside inherent in their accommodation model, as highlighted in this study. That said, while the pursuit of resident wellbeing is a worthy goal for retirement village management to aim for, it should not become an imperative that silences dissent or dissatisfaction. If a person feels that they are being treated poorly or unfairly, there should be processes and spaces for residents to express their dissatisfaction either anonymously or directly to management and staff, without feeling that they are somehow belying the positive ethos of the village. In other words, residents should be entitled to be unhappy where appropriate (Ahmed, 2010). Our research suggests that there are many issues within retirement villages that can conspire against positive experience, and this must be accepted as a fact of working with a vulnerable group and creating environments that are to some degree segregated from younger people.

Much could be done to encourage a more permeable divide between the village and surrounding community, and to prevent social cliques forming, or individuals feeling ostracized, as emphasized by Liddle et al. (2013), in their review of the age-friendliness of retirement communities. From our data and analysis, we suggest that village staff and 
management should make greater efforts to set up joint activities with younger people from the external community, including regular ones in physical locations off-site. Both of these measures prevent the sense of being in a 'grey ghetto', and promote the sense and reality that the village is part of the community, not set away from it. When organising communal activities within the village, much can also be done to prevent cliquing and ostracising, for example in activities, people can be randomly allocated to groups or teams, rather than selfselect themselves into existing cliques. Seating at mealtimes can also be managed, for example at special meals such as Christmas seating can be arranged in advance, rather than self-selected. This limits choice in such instances, but in the process facilitate communication between residents who may find themselves in different social groups, thus lessening the perceived boundaries between them. As a final suggestion, new arrivals can also be assigned a mentor from existing residents, to help smooth the transition into the village, and prevent being ostracised.

\section{Limitations and future directions}

This study has thrown a light on the complexity of life in a retirement village and the challenges that providers of such communities face in maximising the positive, and minimising the negative, in such environments. Inevitably with an exploratory qualitative study, there are limitations inherent in the sample that mean further research on demographically and geographically different samples is essential. The retirement villages from which the sample was recruited were developed for those who were financially secure. This orientation towards relatively wealthy respondents may be why finance did not emerge as a salient issue in relation to wellbeing in the study. It is likely to be a very big issue in other retirement village samples. Furthermore, the sample was limited to those who responded voluntarily to a letter, which biases towards those residents who are sufficiently proactive and prosocial to put themselves forward to speak to a stranger. This is reflected in 
the fact that many descriptions of residents being ostracised or having trouble adjusting were about others in the village, not about themselves or their partner. This issue of having a 'proactive' bias in the sample is an artefact of informed consent as an ethical requirement, and is thus very difficult to get around in another way than observation of a retirement village (Robinson, 2014).

Other methodological limitations include the use of retrospective interview questions about past experiences. Given the fallibility of memory, and particularly so in older adults, it may have been that references to changes to wellbeing before and after the move were limited by recall ability. This would be dealt with by longitudinal research with residents of retirement villages to explore changes over time. After all, life in a retirement village is a dynamic, unfolding experience over time of transition, adjustment and adaptation, and to explore how such adjustment unfolds temporally, and to distinguish the village experience from the more non-specific challenges of aging, a longitudinal study would be a strong additional to the literature. The challenge of such a study is that gaining a sample of participants who are moving to a retirement village is logistically complicated and timeconsuming given the slow turnover of accommodation in many villages. A potentially good way of getting a sample may be to find a brand new retirement village that is gaining lots of new residents in a short space of time, and then following those participants through the transition to their new accommodation and over a period of years. We hope that the current paper provides a useful and integrative framework for more resource- and time-intensive research designs. The study's findings suggest that Ryff's wellbeing model provides a parsimonious and appropriate taxonomic framework for exploring both the presence and absence of wellbeing in the context of a retirement village, and change on these dimensions over time could be explored further in longitudinal work. However the model is a highly inclusive typology that can incorporate many different kinds of wellbeing-valenced 
experiences, and while our study supports is use as an interpretative framework, further hypothesis-driven research is necessary to explicitly test the model.

In conclusion, the positive and negative experiences of life in two UK retirement villages can be accounted for within Ryff's six dimensions of eudaimonic wellbeing. The paradox is that such communities can both undermine and promote all six wellbeing domains, which highlights their ambiguous status as environments of choice for elderly adults; they enable but restrict, connect but disconnect, support yet potentially undermine self-esteem. Any decision to move into a retirement village will be made more informed if both sides of this equation are known, for retirement village publicity literature will inevitably focus solely on the positive side. 


\section{References}

Ayalon, L., \& Green, V. (2012).Grief in the initial adjustment process to the continuing care retirement community. Journal of Aging Studies. 26, 394-400.

Allen, J. (2008). Older people and well-being. England: Institute of Public Health Research. Retrieved $5^{\text {th }}$ February, 2012 from http://www.ippr.org/images/media/files/publication/2011/05/older_people_and_wellb eing1651.pdf

Altintus, E., \& Guerrien, A. (2009).Motivational orientation and depression symptoms in the elderly, Encephale. 35, 115-120.

Ahmed, S. (2010). The promise of happiness. Durham: Duke University Press.

Baurer, J.J., \& Park, S.W. (2010). Growth is not just for the young: growth narratives, eudaimonic resilience, and the aging self. In Fry, P., S., \& Keyes, C., M., L. (Eds.). New frontiers in resilient aging: Life strengths and well-being in late life (pp. 60-89). Cambridge, England: Cambridge University Press.

Bernard, M., Liddle, J., Bartlam, B., Scharf, T., \& Sim, J. (2012). Then and now: evolving community in the context of a retirement village. Ageing and Society, 32, 103-129.

Biggs, S., Bernard, M., Kingston, P., \& Nettleton, H. (2000). Lifestyles of belief: Narrative and culture in a retirement community. Ageing and Society, 20, 649-672.

Braun, V. and Clarke, V. (2006).Using thematic analysis in psychology. Qualitative Research in Psychology, 3, 77-101.

Buys, L.R. (2001). Life in a retirement village: Implications for contact with community and villages. Gerontology, 47, 55-59.

Carr, D.C., \& Manning, L.K. (2010). A new paradigm for qualitative research in the United States: The era of the Third Age. Qualitative Sociology Review, 1, 16-33.

Caro, F.G., Yee, C., Levien, S., Gottleib, A.S., Winter, J., McFadden, D.L., et al. (2012). 
Croucher, K., Hicks, L., \& Jackson, K. (2006). Housing with care for later life: A literature review. Retrieved $29^{\text {th }}$ January, 2012 from http://www.housinglin.org.uk/_library/Resources/Housing/Housing_advice/Housing_ with_care_for_later_life.pdf

Cumming, E., \& Henry, W.E. (1961). Growing Old. New York: Basic.

Cutchin, M.P. (2005).Spaces for inquiry into the role of place for older people's care. Journal of Clinical Nursing, 14, 121-129.

Daatland, S.O. (2005).Quality of life and aging. In Johnson, M., L., Bengston, V., L., Coleman, P.., G., \& Kirkwood, T., B. (Eds.).The Cambridge handbook of age and ageing (pp. 371-377). Cambridge: Cambridge University Press.

Evans, S. (2009). Community and ageing: Maintaining quality of life in housing with care. Bristol, England: The Policy Press.

Gardner, I.L., Browning, C., \&Hendig, H. (2005). Accommodation options in later life: retirement village or community living? Australian Journal of Aging, 24, 188-195.

Gilleard, C. \& Higgs, P. (2005).Contexts of aging: Class, cohort and community. Cambridge: Polity Press.

Glass, A., P., Vander, Plaats, R., (2013). A conceptual model for aging better together intentionally. Journal of Aging Studies. 27, 428-442.

Grant, B. (2007). Retirement villages: More than enclaves for the aged. Activities, Adaption \& Aging, 31, 37-55.

Greenfield, E.A., \& Marks, N. (2004).Formal volunteering as a protective factor for older adults’ psychological well-being. Journals of Gerontology: Series B: Psychological Sciences and Social Sciences, 59B, S258-S264.

Golant, S., M. (2011). The quest for residential normalcy by older adults: relocation but one pathway. Journal of Aging Studies. 25, 193-205. 
Gurney, C., \& Means, R. (1993).The meaning of home in later life. In Arber, S., \& Evandrou, M. (Eds. ). Aging, independence, and the life course (pp. 119-131). London: Jessica Kingsley Publishers.

Hahn, J., \&Oishi, S. (2006). Psychological needs and emotional wellbeing in older and younger Koreans and Americans. Personality and Individual Differences, 40, 689-698.

Hansen, J. (2001). From special needs to lifestyle choices: Articulating the demand for third age housing. In S. Peace \& C. Holland (Eds.).Inclusive housing in an aging society (pp. 29-54). Bristol: Policy Press.

Harris, H. (2008). Growing while growing: Spiritual formation at the end of life. Journal of Religion, Spirituality and aging, 20, 227-245.

Henderson, C. S.,\& Andrews, N. (1998).Partial view: An Alzheimer's journal. Dallas: Southern Methodist University Press.

Huber, J., \& Skidmore, P. (2003).The new old: Why baby boomers won't be pensioned off. London: Demos.

Johnson, C.L., \& Barer, B.M. (1997).Life beyond 85 years: the aura of survivorship. New York: Springer.

Johannesen, A., Petersen, J., \& Avlund, K. (2004). Satisfaction in everyday life for frail 85year-old adults: A Danish population study. Scandinavian Journal of Occupational Therapy, 11, 3-11.

Kastenbaum, R. (1993). Encrusted elders: Arizona and the political spirit of postmodern aging. In Cole, T.R., Achenbaum, W.A., Jakobi, P.L., \& Kastenbaum, R. (Eds.). Voices and visions of aging: Toward a critical gerontology (pp. 160-183). New York: Springer. 
Katz, S. (2009). Spaces of age, Snowbirds, and the gerontology of mobility: The elderscapes of Charlotte country Florida. In Sokolovsky, J. (Ed.). The cultural context of aging: Worldwide perspectives (pp. 463-486). Westport: Greenwood Publishing Group.

Kling, K.C., Seltzer, M.M., \& Ryff, C.D. (1997). Distinctive late-life challenges: Implications for coping and well-being. Psychology and Aging, 12, 288-295.

Laws, G. (1995). Embodiment and emplacement: identities, representation and landscape in Sun City retirement communities. International Journal of Aging and Human Development, 40, 253-280.

Liddle, J., Sharf, T., Bartlam, B, Bernard, M., \&Sim, J. (2013). Assessing the agefriendliness of purpose-built retirement communities: evidence from England. Ageing and Society, First View, 1-29.

Malette, J. \& Oliver, L. (2006). Retirement and existential meaning in the older adults: A qualitative study using Life Review. Counselling, Psychotherapy, and Health, 30-49.

McHugh, K. E. (2000). The ageless self? Emplacement of identities in Sunbelt retirement communities. Journal of Aging Studies, 14, 103-115.

McHugh, K.E., \& Larson-Keagy, E.M. (2005). These white walls: The dialectic of retirement communities. Journal of Aging Studies, 19, 241-256.

Robinson, O.C. (2012). Development through Adulthood: An integrative sourcebook. Basingstoke: Palgrave Macmillan.

Robinson, O., C. (2011). Relational analysis: An add-on technique for aiding data integration in qualitative research. Qualitative Research in Psychology, 8, 197-209.

Robinson, O.C. (2014). Sampling in interview-based qualitative research: a theoretical and Practical guide. Qualitative Research in Psychology, 11, 25-41.

Ryff C., D. (1989). In the eye of the beholder: views of psychological well-being among middle-aged and older adults. Psychology and Aging, 4,195-210. 
Ryff, C.D., \& Singer, B.H. (2008). Know thyself and become what you are: a eudaimonic approach to psychological wellbeing. Journal of Happiness Studies, 9, 13-39.

Ryff, C., D., \& Keyes, C.L.M. (1995). The structural of psychological well-being revisited. Journal of Personality and Social Psychology, 69, 719-727.

Sandhu, N., K., Kemp, C., L., Ball, M., M., Burgess, E., O., \& Perkins, M., M. (2013). Coming together and pulling apart: exploring the influence of functional status on coresident relationships in assisted living. Journal of Aging Studies. 27, 317-329.

Shapiro, J.P. (1999). No sunset for Sun City.US News and World Report, 126, $78-81$.

Tornstam, L. (1989). Gerotranscendence; A reformulation of the disengagement theory. Aging: Clinical and Experimental Research. 1, 55 - 63. 
Figure 1: Positive and negative wellbeing in the context of retirement villages, within Ryff's

\section{(1989b) six-component model}

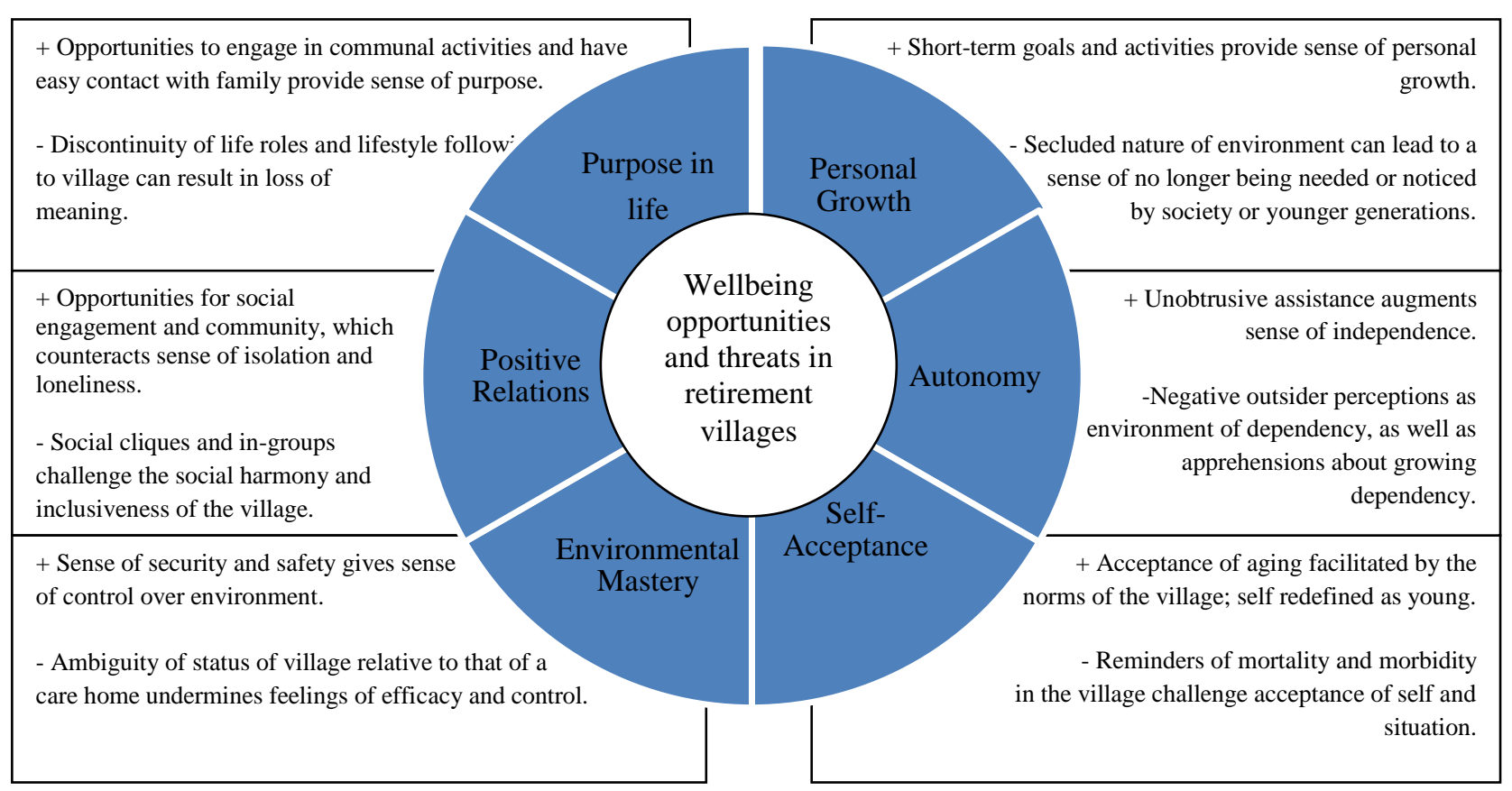


Running title: Wellbeing in retirement villages

Table 1. Details of participants: Pseudonym, age, marital status, duration of residency and factors in decision to move to village

\begin{tabular}{|c|c|c|c|c|}
\hline Pseudonym & Age/s & Marital Status & $\begin{array}{l}\text { Duration of } \\
\text { residency }\end{array}$ & Decision to move \\
\hline Betty \& & 68 & Married & Less than one year & Decision as a couple based on apprehensions, William \\
\hline William & 70 & & & became unwell. \\
\hline Anne \& & 85 & Married & Less than one year & Decision as a couple based on their apprehensions \\
\hline Martin & 85 & & & about getting older. \\
\hline Karen & 77 & $\begin{array}{l}\text { Widowed } \\
\text { (Married when } \\
\text { moved to village) }\end{array}$ & 7 years & $\begin{array}{l}\text { Decision with family involvement based on } \\
\text { apprehensions- husband became unwell. }\end{array}$ \\
\hline Rose & 99 & Spinster & 5 years & $\begin{array}{l}\text { Decision independently based on apprehensions } \\
\text { about getting older }\end{array}$ \\
\hline Emma & 76 & $\begin{array}{l}\text { Widowed } \\
\text { (Married when } \\
\text { moved to village) }\end{array}$ & 2 years & Decision by husband as he became unwell. \\
\hline Lily & 83 & Widowed & 1 year & $\begin{array}{l}\text { Decision with family involvement, based on } \\
\text { apprehensions about getting older and proximity to } \\
\text { family. }\end{array}$ \\
\hline Emily & 91 & $\begin{array}{l}\text { Widowed(Married } \\
\text { when moved to } \\
\text { village) }\end{array}$ & 6 years & $\begin{array}{l}\text { Decision with family involvement based upon } \\
\text { apprehensions about getting older. }\end{array}$ \\
\hline Daisy & 87 & $\begin{array}{l}\text { Widowed } \\
\text { (Married when } \\
\text { moved to village) }\end{array}$ & 6 years & $\begin{array}{l}\text { Decision by husband due to apprehensions about } \\
\text { getting older, and proximity to family. }\end{array}$ \\
\hline Eric & 82 & Widower & 4 years & $\begin{array}{l}\text { Decision with family involvement following the death } \\
\text { of Eric's spouse. }\end{array}$ \\
\hline Dorothy & 84 & Widowed & 1 year & $\begin{array}{l}\text { Decision by husband before his death; the village was } \\
\text { in close proximity to family also. }\end{array}$ \\
\hline Kate \& & 89 & Married & 3 years & Decision with family involvement; the village was in \\
\hline James & 89 & & & close proximity to family. \\
\hline Ellen & 89 & Widowed & 1 year & $\begin{array}{l}\text { Decision independent; the village was in close } \\
\text { proximity to family. }\end{array}$ \\
\hline Martha & 85 & Widowed & 12 years & $\begin{array}{l}\text { Decision with family involvement due to } \\
\text { apprehensions about getting older. }\end{array}$ \\
\hline Louise & 85 & Widowed & 6 years & $\begin{array}{l}\text { Decision independent due to death of spouse and } \\
\text { apprehensions about getting older. }\end{array}$ \\
\hline Norah & 88 & $\begin{array}{l}\text { Widowed } \\
\text { (Married when } \\
\text { moved to village) }\end{array}$ & 11 years & $\begin{array}{l}\text { Decision by husband due to apprehensions about } \\
\text { getting older and proximity to family. }\end{array}$ \\
\hline
\end{tabular}


Running title: Wellbeing in retirement villages

\section{APPENDIX A}

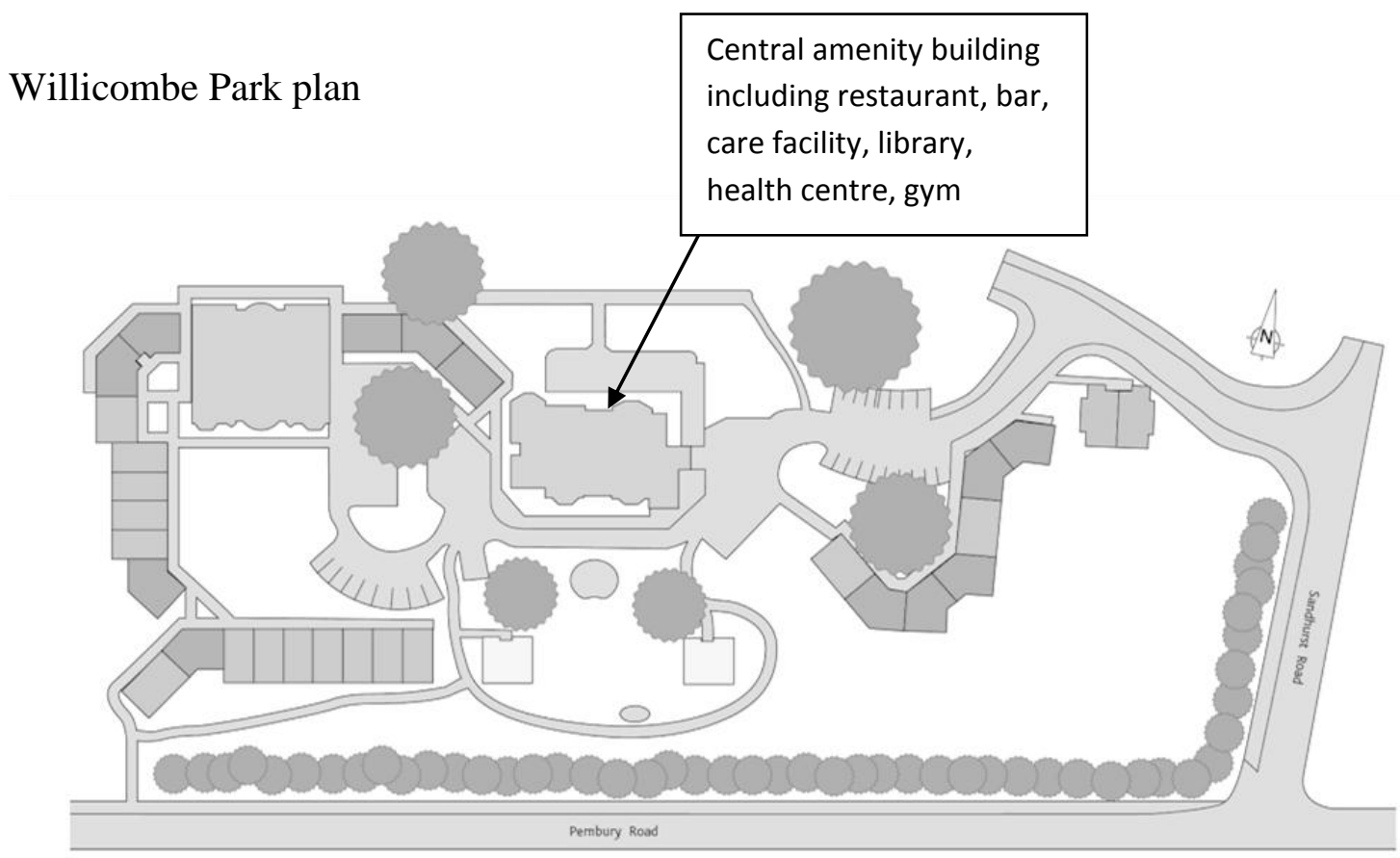

Mote house plan

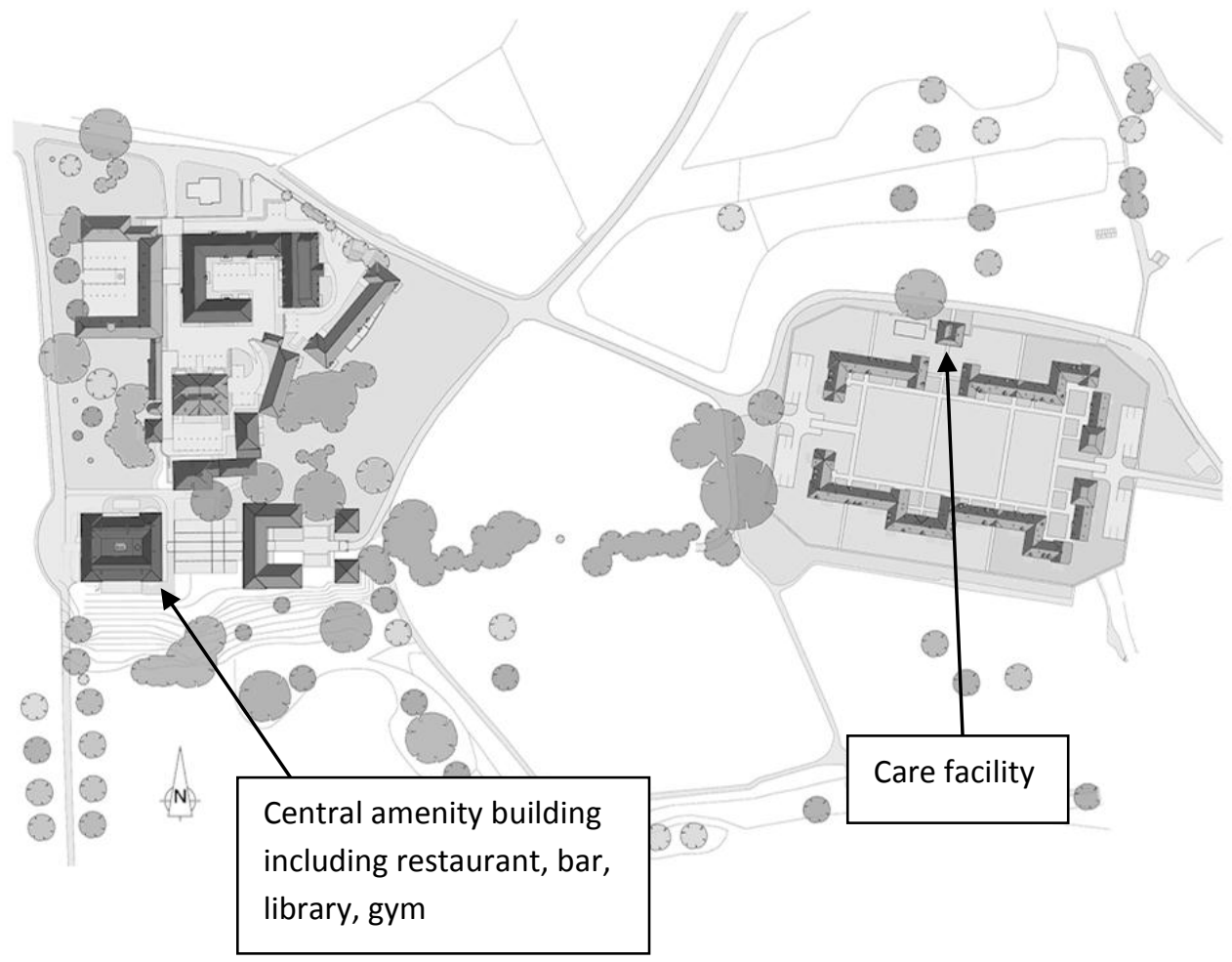

Page 31 of 31 